\title{
Molecularly Imprinted Polymer Pearls Obtained by Phase Inversion for the Selective Recognition of Hypericin
}

\begin{abstract}
ANA-MIHAELA (FLOREA) GAVRILA ${ }^{1 *}$, TANTA-VERONA IORDACHE ${ }^{1 *}$, TEODOR SANDU' ${ }^{1}$, ANAMARIA ZAHARIA ${ }^{1}$, ANITA-LAURA RADU ${ }^{1}$, CATHERINE BRANGER ${ }^{2}$, HUGUES BRISSET ${ }^{2}$, ELENA-BIANCA STOICA ${ }^{1}$, STELUTA APOSTOL ${ }^{1}$, ANDREI SARBU ${ }^{1 *}$

${ }^{1}$ National Research and Development Institute for Chemistry and Petrochemistry ICECHIM, Advanced Polymer Materials and Polymer Recycling, 202 Splaiul Independentei, 060021 Bucharest, Romania.

2Laboratoire MAPIEM, EA 4323, Universite de Toulon, CS 60584, 83041 Toulon Cedex 9, France

A facile and inexpensive approach was established to prepare spherical molecularly imprinted polymers with hypericin (H-MIPs) via the wet-phase inversion method. The H-MIPs were characterized by infrared spectroscopy and thermogravimetric analysis. High-performance liquid chromatography combined with UV-Visible spectroscopy were used to assess the efficiency of the extraction procedure and, furthermore, to investigate the recognition properties of the H-MIPs. Obtaining an imprinting factor of 3.38 for hypericin strongly indicated a successful formation of molecularly imprinted cavities onto the H-MIPS. A fair selectivity towards hypericin was tested in comparison to the interfering molecule pseudohypericin.
\end{abstract}

Keywords: molecular imprinting, wet-phase inversion, pearls, hypericin

In the last years, the molecular imprinting technique (MIT) has proven to be a versatile and low-complexity chemical method for the production of highly selective artificial receptors towards given molecules (templates). MIT is bio-inspired from the well known key in the lock principle, postulating that only one key fits in the lock [13]. By using MIT, low cost and high stability materials (known as molecularly imprinted polymers, MIPs), containing cavities able to recognize selectively templates ranging from valuable or toxic small molecules can be easily prepared. Consequently, these attributes make MIPs ideal for replacing the extensive materials commonly used in solid-phase extraction [4,5], drug delivery [6], sensors $[7,8]$ and purification and separation [9-11].

The template used in this work was hypericin, one of the most important bioactive metabolite isolated from St. J ohn's Wort plant (Hypericum perforatum L.). Belonging to naphthodianthrones (NTS) group, hypericin has gained increasing interest recently due to its potential as a highly effective anti-depressant and anti-tumor agent [12, 13]. Isolation and purification of hypericin (which coexists in very low amounts with pseudohypericin, $\mathrm{PH}$ - structural analogue) from the plant itself is a great challenge due to its poor solubility and degradation upon exposure to heat and light [14]. Thus, to improve the extraction process of hypericin simplified procedures that allow efficient and quantitative separation are still on high demand.

In this respect, the preparation of MIPs using wet-phase inversion is of great interest in the fields of separations and sensors due to the high economical potential, simple principle and well-established technological background [15-17]. The principle of this procedure is that a mixture of polymer and target molecules of interest is prepared in a casting solvent, and then imprinted polymer films, membranes or pearls are created. The chemical crosslinking step (usually performed as the imprinting step in MIT) is replaced by a physical crosslinking of the polymer precursors, via hydrogen bonds, obtained either by solvent evaporation (dryinversion) or by precipitation in non-solvent (wet inversion). The last stage of this procedure is the same as for all MIP preparation procedures, meaning template removal from the solid polymer structure [16].
Recently, our group applied the wet-phase inversion method to produce MIP pearls able to selectively separate hypericin from Hypericum Perforatum L. primary extracts $[18,19]$. By this way, hypericin molecules can be generated from concentrated NTs extracts in situ, meaning along with the phase inversion of the copolymer. Moreover, this attractive technique was adapted by our group in order to prepare 2,4,6-trinitrotoluene (TNT) MIP films used further as potential recognition elements for TNT-sensor devices [20]. To this day, few reports on hypericin-MIPs have been published in the literature. For instance, Pei etal. prepared molecularly imprinted nanospheres, via click reactions (azide-alkyne and thiol-yne) and surface imprinting techniques, using core-shell magnetic MIP [21, 22].

Hence, the present work aims atexploring the possibility of using the simpler and more economic wet-phase inversion method to prepare MIP pearls with pure hypericin as template (noted H-MIPs) and methacrylic acid (MAA) and acrylonitrile (AN) as functional monomers. Appling this method, two pearls systems imprinted with either 5 wt. $\%$ or 10 wt. $\%$ hypericin and containing 20 wt.\% or 25 wt.\%MAA ratios were successfully prepared. The properties of the H-MIPs, such as adsorption capacity, imprinting factor and selectivity, evaluated by chromatographic techniques indicated that the obtained MIPs have great potential to be used as separation materials for NTs.

\section{Experimental part \\ Materials}

The acrylonitrile (AN, $98 \%$ ) and methacrylic acid (MAA, 99\%) monomers used for the synthesis of copolymers were purchased from ACROS Organics. AN and MAA were purified prior to use by distillation. Dimethylsulfoxide (DMSO, p.a. grade) and ethanol (EtOH, 99.6\%) used for the preparation of precursor solutions and washing, respectively, were purchased from Scharlau or Chimopar and used without further purification. The commercial hypericin $(H, 99 \%)$ used as template for the imprinting procedure was supplied by Sigma-Aldrich. The hydroalcoholic extract (30/70, v/v) containing hypericin and its structural analog pseudohypericin $(0.25 \mathrm{~g} / \mathrm{L} \mathrm{NTs,} \mathrm{from}$ 
Plantavorel Romania) was used as received. Distilled water used throughout the experiments was obtained from a laboratory purification system.

\section{Instrumentation}

For the structural analyses, the pearls were dried at 50 ${ }^{\circ} \mathrm{C}$ until constant weight (around $24 \mathrm{~h}$ ). FTIR spectra were registered on a Fourier transform infrared spectrometer Bruker Tensor 37 Spectrometer (ATR device) in the 400$4000 \mathrm{~cm}^{-1}$ range using 16 scans with a $4 \mathrm{~cm}^{-1}$ resolution. Thermogravimetric analysis (TGA/DTG) was performed on a Q500 TA Instrument. The samples were heated from room temperature to $800^{\circ} \mathrm{C}$ at a scanning rate of $10^{\circ} \mathrm{C} / \mathrm{min}$ under a constant nitrogen flow rate. All binding and selectivity experiments were performed using a HPLC (Varian Prostar, Prostar 350 autosampler) equipped with a Mediterranea SEA C18, $5 \mu \mathrm{m} 15 \times 0.46 \mathrm{~cm}$ column (Teknokroma) and a diode array detector (DAD) at 593 $\mathrm{nm}$. In order to detect the concentration of NTs in the 400$800 \mathrm{~nm}$ wavelength range and to quantify the selectivity parameters of pearls, a UV-vis Spectrometer Thermo Nicolet Evolution 500 was used.

\section{Preparation of MIP and NIP pearls}

The two series of hypericin-MIPs (H-MIPs), based on poly(AN-Co-MAA) synthesized with either 20 or $25 \mathrm{wt} . \%$ $M A A$, where the template amount varied from 5 to $10 \mathrm{wt} . \%$ hypericin were prepared according to a previous reported wet-phase inversion method [19]. The pearls were noted hereafter MIP 20-5/ MIP 20-10 and MIP 25-5/ MIP 25-10. This method also describes the preparation of the AN-MAA copolymer used as precursor for the pearls matrix. For short, poly(AN-co-MAA) was synthesized according to a soapfree emulsion polymerization, using two weight ratios of AN and MAA (i.e. 80:20 and 75:25 wt.\%, respectively). In light-protected flasks, MIP precursor solutions were obtained by dissolving $8 \mathrm{wt}$. \% poly(AN-co-MAA) into DMSO $\left(100 \mathrm{~mL}\right.$ ) at around $80^{\circ} \mathrm{C}$, and then the template hypericin ( 5 or 10 wt.\% calculated to the polymer) was added at room temperature. The solutions were introduced into a syringe-like cartridge of the semi-automated dripping system that converted the copolymer droplets into polymer pearls at contact with the water coagulation bath. The phase inversion was complete after $24 \mathrm{~h}$ and the pearls were collected from the water bath. Extraction of hypericin from the H-MIPs, performed in order to generate the specific binding sites, was accomplished by washing the pearls several times with distilled water to remove DMSO ( $25 \mathrm{~mL}$ per portion / phase) and with ethanol ( $25 \mathrm{~mL}$ per portion / phase, 4h under continuous stirring) to remove hypericin. Finally, some pearls were dried for further characterization and rest of the pearls were kept in ethanol to prevent drying/ shrinking. Non-imprinted polymer pearls (noted NIP 20-5, NIP 20-10 and NIP 25-5, NIP 25-10) were prepared in the same manner as the H-MIPs but without template and served as control samples.

\section{Batch binding and selectivity experiments}

$600 \mathrm{mg}$ of wet pearls were mixed with $3 \mathrm{~mL}$ of hypericin\&pseudohypericin hydro-alcoholic solution or NTS phyto-extract $(0.025 \mathrm{wt} . \%)$, properly diluted in the $10^{-4}-10^{-5}$ mole/L range, at room temperature. After $24 \mathrm{~h}$ the supernatants were collected and analyzed by HPLC equipped with an UV-vis detector (DAD). Because of their high structural resemblance, hypericin and pseudohypericin adsorb light in a close wavelength range (593 and $592 \mathrm{~nm}$, respectively). The imprinting effect of hypericin was determined by HPLC and the selectivity of pearls was analyzed by UV-vis spectroscopy in the presence of pseudohypericin. Conditions HPLC: mobile phasemethanol/20 mM K $\mathrm{HPO}_{4}$ ( $p \mathrm{H}$ 7.0) 90:10 adjusted to $\mathrm{pH}$ 5.5 with phosphoric acid; Isocratic mode, $1 \mathrm{~mL} / \mathrm{min}$ flow rate, $10 \mu \mathrm{L}$ injection volume.

The amounts of adsorbed hypericin and pseudohypericin (or binding capacity $Q$, g compound/g pearls) were calculated by subtracting the supernatant concentrations from the initial concentrations of hypericin and pseudohypericin, respectively, in solution (eq. 1). The imprinting factor, IF, quantified the specificity with which the MIP adsorbed hypericin relative to the NIP, and was determined as the ratio between the binding capacity of the MIP and that of the NIP (eq. 2).

$$
\begin{gathered}
Q=\text { (initial concentration -supernatant concentration) } \\
* \text { volume } / \text { polymer weight }(g) \\
\text { IF }=Q_{M I P} / Q_{N \mid P}
\end{gathered}
$$

The distribution coefficient $K_{d}(\mathrm{~mL} / \mathrm{g})$ represented the amount of compound $C n$, bounded by $1 \mathrm{~g}$ of pearls, relative to the amount of the same compound remaining in $1 \mathrm{~mL}$ of feed extract (eq. 3). Selectivity coefficient, $k$, (eq. 4) quantifies the binding affinity of MIPs for hypericin over its competitor (pseudohypericin); where the notation C1-C2 represented the hypericin-pseudohypericin. A relative selectivity coefficient, $k^{\prime}$ was also defined in eq. 5), which expresses the selectivity of MIPs in competitive adsorption relative to blank pearls-NIPs. The binding experiment was carried out in duplicate and the reproducibility was found to be $\pm 2 \%$.

$K_{d c n}=$ (initial concentration -supernatant concentration)

$*^{d}$ volume/initial concentration* polymer weight $(g)$

$$
\begin{aligned}
& k_{C 1-C 2}=K_{d C 1} / K_{q C 2} \\
& k_{C 1}=k_{C 1-C 2, M I P} / k_{C 1-C 2, N I P}
\end{aligned}
$$

\section{Results and discussions}

\section{Properties of pearls}

The choice of copolymer matrices as optimum precursors for imprinting is crucial. In our previous study, we proved that both the MIP and the NIP pearls presented tails at decreasing content of MAA and of hydro-alcoholic extract extract in the feed solutions [19]. Hence, in order to achieve the formation of tailless pearls following the phase inversion, precursor copolymers with 20 and 25\% MAA were used. As seen in figure 1, the addition of pure hypericin (instead of extract [19]), in the form of a hydroalcoholic NTs extract solution, showed the same effect on the shape of the pearls, with no tails. It is worth mentioning that the imprinted pearls were rose-pink derived from the red-colored hypericin (fig. $1 \mathrm{a}$ and b). Furthermore, imprinting with $10 \%$ hypericin leads to a much more pronounced dyeing of pearls (fig. 1 b). From figure $1 \mathrm{c}$ and $d$, itcan be observed that the pink colour disappears upon hypericin extraction.

Hydrodynamic measurement of the internal pore volume of imprinted $\mathrm{H}$ pearls, $\boldsymbol{V}(\%)$ revealed a high pore volume between $89-92 \%$ relative to total pearl volume, $V_{p}(\mathrm{~mL})$ (table 1). The results indicated lower values for the pore volume for NIP pearls compared to the MIP ones, probably due to the absence of the template during the formation of pearls. Moreover, pearls with a higher pore volume were obtained when the content of MAA in the copolymer was higher, i.e. $25 \mathrm{wt}$.\%. This result arise from the fact that the AN-MAA copolymers with higher MAA content are more hydrophylic and swell in water. Hence, imprinting with pure hypericin leads to higher pore volumes (from about $88 \%$ to 


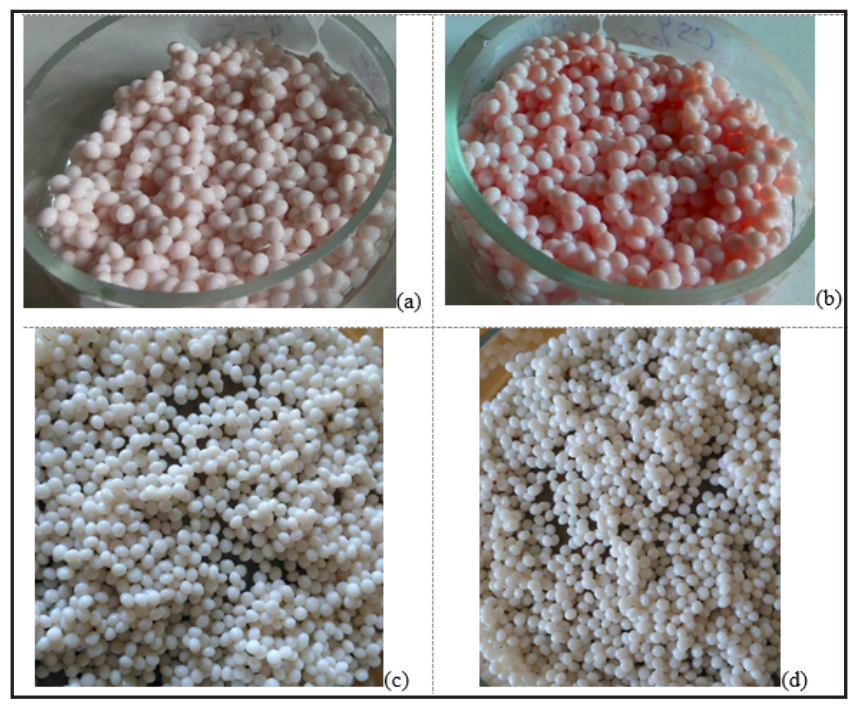

Fig. 1. Example of wet MIPs pearls obtained by wet phase inversion: (a) MIP 20-5 and (b) MIP 25-10 (c) MIP 20-5 after hypericin extraction and (d) MIP 25-10 after hypericin extraction

92\%) compared to values obtained in our previous studies $[19,23]$.

By analyzing the water resulted from the phase inversion bath it was possible to quantify the total amount of hypericin that was imprinted in the pearls (table 1 ). For pearls imprinted with 5 wt.\% hypericin over $94 \%$ was imprinted in the pearls and for the pearls with $10 \mathrm{wt} \%$ hypericin, more than $99 \%$. This can be explained by the fact that hypericin is prone to form homo-associations of 3-5 molecules at high concentrations, which are even less soluble in water. This phenomenon was confirmed by the less successful extraction procedure for the MIP 20-10 and MIP $25-10$ ( $41 \%$ and $56 \%)$, indicating that half of the hypericin was still trapped in the matrix after extraction. Therefore, the process was repeated for the two types of MIP pearls until the pearls were colorless. On the other hand, more than $85 \%$ of hypericin was extracted from MIP
25-5 and around 70\% from MIP 20-5. The explanation for the more efficient extraction of hypericin in this case can be correlated with the higher pore volume of these pearls, which favors the release of hypericin.

\section{FTIR Analysis}

To confirm the presence of the monomers and the efficiency of hypericin extraction procedure, the MIPs were analyzed using FTIR spectroscopy before and after hypericin extraction. The spectrum of pure hypericin is shown in figure 2. Hypericin exhibit typical bands of naphthodianthrones. Wide $v$ bands (intramolecular hydrogen bonding) appear at $3448 \mathrm{~cm}^{-1}$, accompanied by $v_{\mathrm{co}}\left(\mathrm{Ar}-\mathrm{OH}\right.$ ) in the $1229-1744 \mathrm{~cm}^{-1}$ range (where quinones have intense bands assigned to the carbonyl groups). The bands from $2926 \mathrm{~cm}^{-1}$ and $2960 \mathrm{~cm}^{-1}$, respectively, correspond to stretching vibrations of $\mathrm{CH}$ and $\mathrm{CH}_{2}$ groups.

As shown in table 2, the H-MIPs before and after template extraction, show distinctive bands in the $2934-2960 \mathrm{~cm}^{-1}$ range which can be assigned to $v_{\text {s }}$ stretching vibrations from the polymer backbone. In the $2242-2252 \mathrm{~cm}^{-1}$ region, bands corresponding to $v_{-\mathrm{Ca}=\mathrm{N}}$ from AN were observed and the bands appearing in the $3704-3296 \mathrm{~cm}^{-1}$ and $1714-1732$

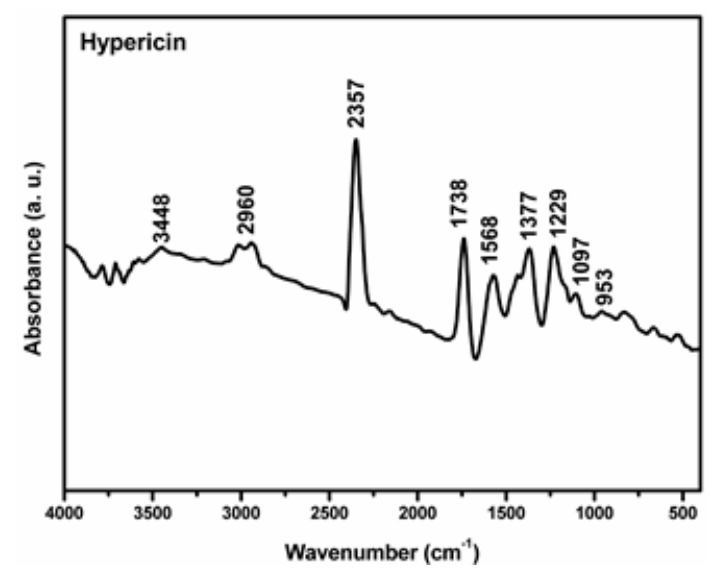

Fig. 2. FTIR spectra of pure hypericin

\begin{tabular}{|c|c|c|c|c|c|}
\hline Polymer & $\begin{array}{l}\mathbf{m}_{\mathrm{p}}^{(1)} \\
(\mathrm{mg})\end{array}$ & $\begin{array}{l}V_{\mathrm{w}} \sim \mathrm{V}_{\mathrm{p}^{(2)}} \\
\quad(\mathrm{mL})\end{array}$ & $V^{(3)}(\%)$ & $\begin{array}{l}\text { Hypericin in bath after } \\
\text { imprinting (\%) }\end{array}$ & $\begin{array}{c}\text { Hypericin } \\
\text { extracted } \\
(\%)\end{array}$ \\
\hline MIP 20-5 & 40.6 & 0.56 & 90.17 & 6.46 & 69.65 \\
\hline NIP 20-5 & 90.7 & 0.51 & 82.10 & - & - \\
\hline MIP 20-10 & 43.1 & 0.56 & 89.77 & 0.90 & 41.22 \\
\hline NIP 20-10 & 95.7 & 0.50 & 81.29 & - & - \\
\hline MIP 25-5 & 40.4 & 0.56 & 91.74 & 2.99 & 84.84 \\
\hline NIP 25-5 & 58.5 & 0.54 & 88.39 & - & - \\
\hline MIP 25-10 & 44.4 & 0.56 & 90.69 & 0.66 & 56.45 \\
\hline NIP 25-10 & 62.6 & 0.54 & 87.72 & - & - \\
\hline
\end{tabular}

(1) $\mathrm{m}_{\mathrm{p}}$, the weight of dried pearls (600 $\mathrm{mg}$ of wet sample);

${ }^{(2)} V_{w}$, the water volume determined thermo-gravimetrically (values of water volume were equivalent to the pore volume, $V_{p}$ );

(3) $\mathrm{V}$, the mean pore volume calculated relative to the hydrodynamic volume of wet pearls;

(4) The initial amount of hypericin for MIP 20-5 and MIP 25-5 and MIP 20-10 and MIP 25-10 is $0.16 \mathrm{mg}$ and $0.32 \mathrm{mg}$, respectively; the amount of water in the inversion bath was $1 \mathrm{~L}$.

\begin{tabular}{|c|c|c|c|c|c|c|c|}
\hline Polymer* & $\begin{array}{c}\text { voH } \\
(\cdots H \cdots)\end{array}$ & $\begin{array}{c}\text { VC_H } \\
\text { (alkyl) }\end{array}$ & $v_{C}=\mathrm{N}$ & $\begin{array}{c}v_{\mathrm{C}=0} \\
(-\mathrm{COOH})\end{array}$ & vech3 & $\begin{array}{c}\text { vc-O- } \\
(\mathrm{Ar}-\mathrm{OH})\end{array}$ & $\begin{array}{l}v_{c-0}, v_{C}=0 \\
(\mathrm{Ar}-\mathrm{COH})\end{array}$ \\
\hline MIP 20-5 be & $3678-3296$ & 2934 & 2245 & 1714 & 1450 & $1361 / 1222$ & 1019 \\
\hline MIP 20-5 ae & $3704-3403$ & 2940 & 2242 & 1729 & 1455 & - & - \\
\hline MIP 20-10 be & $3699-3368$ & 2945 & 2245 & 1726 & 1457 & $1360 / 1218$ & 1017 \\
\hline MIP 20-10 ae & $3692-3315$ & 2940 & 2244 & 1727 & 1458 & - & - \\
\hline MIP 25-5 be & 3464 & 2951 & 2250 & 1724 & 1455 & $1365 / 1218$ & 1137 \\
\hline MIP 25-5 ae & 3429 & 2960 & 2252 & 1726 & 1462 & - & - \\
\hline MIP 25-10 be & 3539 & 2944 & 2251 & 1732 & 1466 & $1362 / 1226$ & 1136 \\
\hline MIP 25-10 ae & 3525 & 2951 & 2252 & 1735 & 1469 & - & - \\
\hline
\end{tabular}

Table 1

CHARACTERISTICS OF MIPS AND NIPS: PORE VOLUME, AMOUNT OF HYPERICIN FOUND IN WATER BATH RELATIVE TO THE INITIAL AMOUNT, AMOUNT OF HYPERICIN AFTER EXTRACTION

Table 2

MAIN CHARACTERISTIC INFRARED BANDS FOR MIP PEARLS BEFORE AND AFTER HYPERICIN EXTRACTION 
$\mathrm{cm}^{-1}$ range were characteristic for the stretching vibrations of $-\mathrm{OH}$ and $-\mathrm{C}=\mathrm{O}$ groups, respectively, from the carboxyl functionality of MAA. It is relevant to point out that the bands corresponding to the aromatic -OH groups overlap of hypericin with the -OH groups of MAA. Hence, the imprinting effect was mostly highlighted by the shifting of $v_{\text {- }}$ (from MAA) due to interactions with hypericin. Polymer-template interactions were also distinguished in the H-MIPs before hypericin extraction, as summarized in table 2. As for H-MIPs pearls with a higher amount of hypericin (10\%), there is a shift of bands to higher wavelengths due to the formation of homoassociates of 35 molecules of hypericin which prevent the establishment of stronger interactions within the polymeric matrix. The extraction of hypericin from the MIPs (see MIPs after extraction) was confirmed by the absence of major characteristic band of hypericin for the quinoid form of naphthodianthrones, at around $1360 \mathrm{~cm}^{-1}$ (C-O stretching vibration). FTIR results also validate the efficiency of the template extraction procedure.

\section{Thermal properties}

The obtained results indicate that the imprinted pearls obtained by phase inversion are relative thermally stable (fig. 3. and fig. 4.). Thermal degradation does not occur completely as a result of the cyclization phenomenon, which is characteristic for polymers with high contents of AN (-CN pendant groups. Thus, for both series of MIPs after extraction of hypericin, residues up to $38 \%$ are formed (fig. 3. and fig. 4. a). For the pearls before hypericin extraction, a lower residue amount was noticed due the steric hindrance of hypericin that prevented cyclization of $-\mathrm{CN}$ fragments. The $10^{\circ} \mathrm{C}$ movement of the maximum cyclization temperature confirms this hypothesis.

The decomposition of statistical copolymer chain takes place in several stages (fig. 3. b). Due to the occurrence of template-intramolecular hypericin bonds, the imprinted pearls are more stable and exhibit a more homogeneous degradation of the polymer, as indicated by the less noticeable shoulder (shifted to higher degradation temperatures). Curves recorded for MIP 20 pearls after extraction exhibited lower degradation rates than those of non-extracted pearls. The weight loss around $172{ }^{\circ} \mathrm{C}$ may be assigned to hypericin degradation (demethylation), as hypericin is thermo-sensitive. Then, a new thermal degradation step occurs, with a peak at about $250^{\circ} \mathrm{C}$ (clear cyclization peak). The last decomposition step for the MIP 20-5 has a maximum at $389^{\circ} \mathrm{C}$ (before hypericin extraction) and $403^{\circ} \mathrm{C}$ (after hypericin extraction). This last stage shows in both cases a shoulder around $320^{\circ} \mathrm{C}$, which is more intense for the extracted pearls.

The thermal degradation of MIP 25-5 (fig. 4. b) is similar to that of MIP 20-5. The only difference was related to lower temperature maxima recorded for each decomposition step. This behavior may be due to the increase in the MAA content from 20 to $25 \%$, which implicitly leads to a quantitative increase of - $\mathrm{COOH}$ groups and less residue. It was also observed that the MIPs imprinted with $10 \%$ hypericin exhibited lower weightlosses compared to those with $5 \%$ hypericin.

\section{Imprinting studies of polymers}

The imprinting effect was quantified for hypericin. Rebinding properties of hypericin demonstrated a strong imprinting effect on all MIP pearls, these pearls adsorbing hypericin nearly three times more than the corresponding NIPs (table 3). High values of binding capacities were recorded for the pearls synthesized with $5 \%$ hypericin, i.e. MIP 20-5 and MIP 25-5. The maximum value for the binding capacity recorded for MIP $25-5,2.65 \mathrm{mg} / \mathrm{g}$ was relative high considering the high content of MAA in the polymer matrix and the low content of hypericin used in the synthesis. This effect was also observed when imprinting with a NTs extract [19]. Yet, herein the use of pure hypericin led to higher values of the adsorption capacities. This behaviour also correlates well with the recorded pore volume for the H-MIP pearls (which was with $4 \%$ higher than the NTs-MIP pearls obtained in the previous study [19]). Furthermore, the difference of binding affinities for hypericin, between the H-MIP and the control NIP, clearly indicates the effect of imprinting with the formation of specific binding sites for hypericin.

The H-MIP pearls exhibited higher affinities for hypericin, than the non-imprinted ones leading to maximum
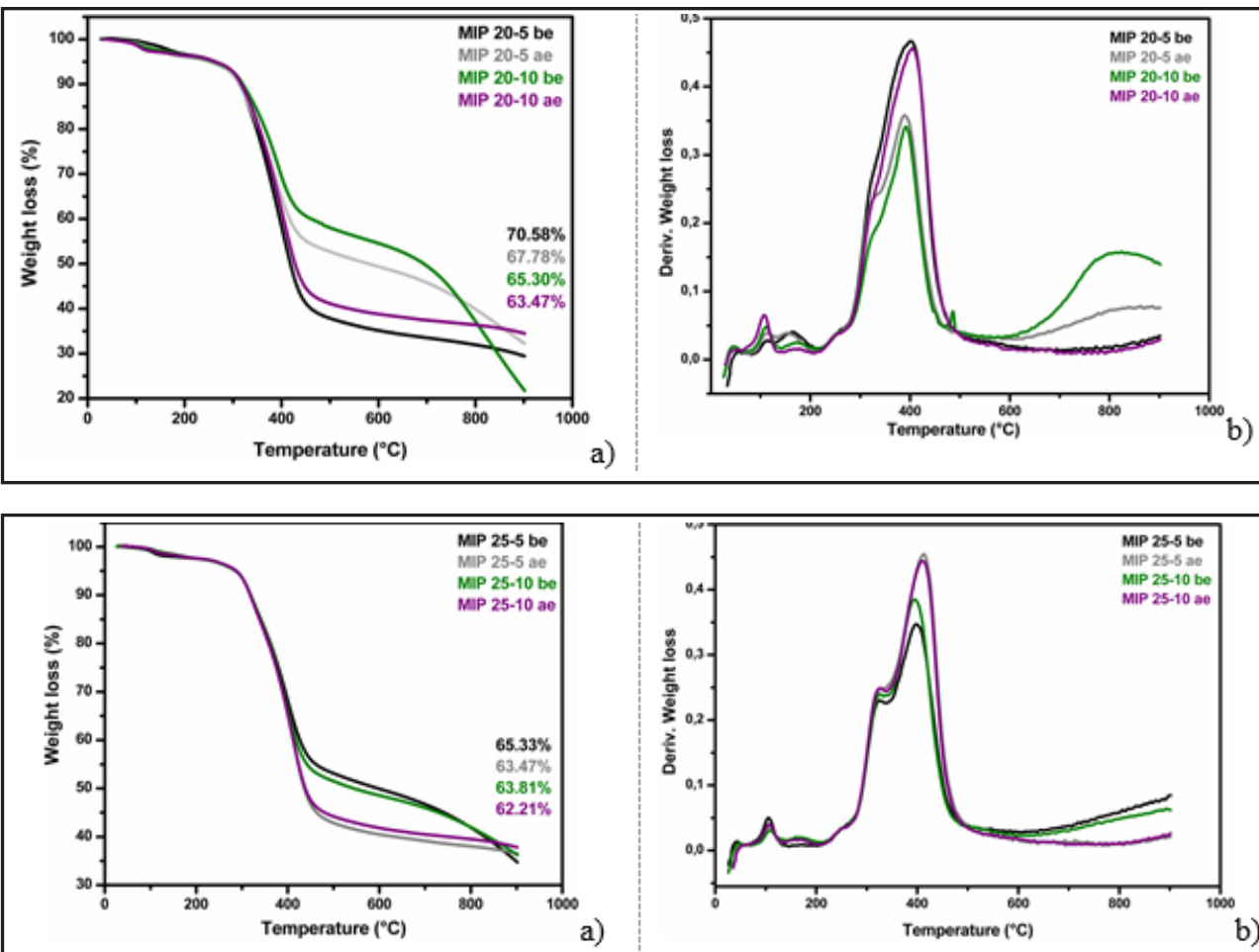

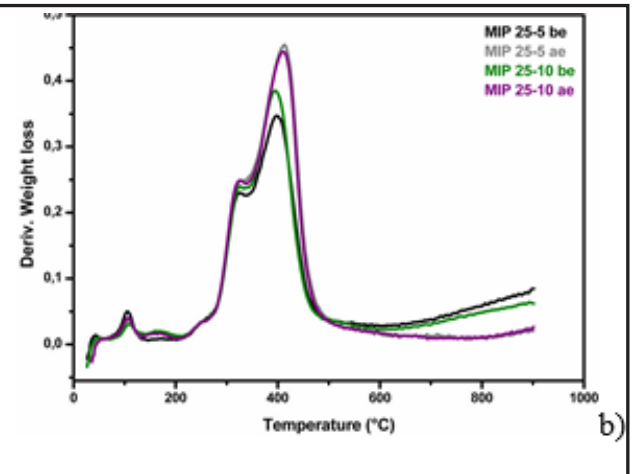

Fig. 4. TGA (a) and DTG (b) curves for MIP 25-5 and MIP 25-10, before and after hypericin extraction 


\begin{tabular}{|c|c|c|c|c|c|c|}
\hline Polymer & $\begin{array}{c}\mathbf{Q} \\
(\mathbf{m g} / \mathbf{g})\end{array}$ & $\mathbf{I F}$ & $\begin{array}{c}\mathbf{K}_{\mathbf{d} \text { hypericin }} \\
(\mathbf{m L} / \mathbf{g})\end{array}$ & $\begin{array}{c}\mathbf{K}_{\text {d preudobypericin }} \\
(\mathbf{m L} / \mathbf{g})\end{array}$ & $\mathbf{k}$ & $\mathbf{k}$, \\
\hline MIP 20-5 & 2.37 & $\mathbf{2 . 9 5}$ & 28.45 & 30.93 & 0.92 & $\mathbf{1 . 2 6}$ \\
\hline NIP 20-5 & 0.8 & - & 8.82 & 12.09 & 0.73 & - \\
\hline MIP 20-10 & 2.13 & $\mathbf{2 . 7 9}$ & 25.06 & 28.87 & 0.97 & $\mathbf{1 . 3 2}$ \\
\hline NIP 20-10 & 0.6 & - & 8.36 & 11.46 & 0.73 & - \\
\hline MIP 25-5 & $\mathbf{2 . 6 5}$ & $\mathbf{3 . 3 8}$ & $\mathbf{3 3 . 2 4}$ & $\mathbf{3 4 . 0 4}$ & 0.97 & $\mathbf{1 . 0 7}$ \\
\hline NIP 25-5 & 0.78 & - & 7.82 & 8.58 & 0.91 & - \\
\hline MIP 25-10 & 2.11 & $\mathbf{2 . 8 8}$ & 25.14 & 24.23 & 1.03 & 1.13 \\
\hline NIP 25-10 & 0.9 & - & 7.34 & 8.05 & 0.91 & - \\
\hline
\end{tabular}

Table 3

BINDING PARAMETERS OF THE POLYMER: ADSORPTION CAPACITY, IMPRINTING FACTOR, DISTRIBUTION COEFFICIENT, SELECTIVITY AND RELATIVE SELECTIVITY COEFFICIENTS imprinting factor, IF, of 3.38 for MIP 25-5 (table 3). As expected, the imprinting factor showed high values for all imprinted pearls due to the imprinting effect. However, the adsorption for hypericin was found to be higher for pearls obtained with a lower amount of template, i.e. MIP x-5. Specific cavities were formed when intermolecular interactions were minimal, i.e. MIP 25-5. The theory of molecular imprinting explains this behavior referring to the concentration effect that prevents the formation of homogeneous cavities in terms of binding energy. Thus, higher amounts of template can generate a larger number of cavities, but their binding energies are different because the template molecules interact with each other during imprinting, which leads to different conformations; therefore, cavities have different levels of energy.

In the selectivity experiment, the target molecule hypericin and the competitive one pseudohypericin possess similar structure and co-exist in Hypericum extract as bioactive components. Selectivity of MIPs towards pseudohypericin was studied by contacting the imprinted and non-imprinted pearls in contact with the NTs extract, which contained around 40\% hypericin and 60\% pseudohypericin [19]. The parameters of the selectivity experiments are show $n$ in Table 3. The Hypericum extract contains more pseudohypericin than hypericin and, as a result, the distribution coefficient $K_{d}$ values for pseudohypericin are higher compared to those for hypericin. Based on the values of $K_{d^{\prime}}$ there was no significant difference of rebinding hypericin and pseudohypericin with NIPs ( $k=0.73$ and 0.91$)$. However, MIPs present close values of adsorption selectivities $(k)$ for hypericin (maximum value of 1.03 for MIP 25-10). The low range of $k$ values was in agreement with the very similar quinone structures of hypericin and pseudohypericin. Moreover, it can also be observed that the selectivity was influenced by the MAA content in the polymer matrix. Overall, the relative selectivity coefficients $k^{\prime}$ confirm that the selectivity of hypericin-MIPs was higher than that of corresponding NIPs which suggested the imprinting effect with hypericin.

\section{Conclusions}

In conclusion, pearl shaped MIPs with reproducible properties were synthesized via wet phase inversion using MAA as functional monomer and AN as structural monomer and pure hypericin as the template. The structure and thermal stability of the resulted MIPs were characterized using FTIR and TGA. Hydrodynamic measurements of the hypericin-MIP pearls revealed a dense porous structure with high pore volumes of about 92 vol.\%. The extraction procedure of hypericin from the MIP pearls was more efficient for the MIP X-5 pearls due to their high pore volume that favored a quantitative extraction. The polymer with the highest content of MAA i.e. MIP 25-5 show ed high adsorption capacities $\left(Q=2.65 \mathrm{mg} \mathrm{g}^{-1}\right)$ but fair selectivity towards hypericin against pseudohypericin, compared to our previous paper [19, 23]. However, the value of the imprinting factor ( IF $=3.38$ ) recorded for MIP 25-5 was in agreement with the relative selectivity coefficients, $k^{\prime}$. Overall, the reported strategy for preparing hypericin-MIP pearls is efficient and the use of pure hypericin in the imprinting step leads to good imprinting parameters of polymers. Therefore, the adsorbentmaterials can be used to obtain more concentrated hypericin solutions.

AcknowledgmentsThe authors thank for the help and support of the Romanian Ministry of Research and Innovation (MCl) and the Executive Unit for Financing Higher Education, Research, Development and Innovation (UEFISCDI) through Project NUCLEU PN.19.23.02.01. and also the $E U$ in the frame of the collaborative international consortium (39/2017-ProWsper) financed underthe ERA-NET Cofund WaterWorks2015 Call.

\section{References}

1. POLYAKOV, M.V., Zhur. Fiz. Khim., 2, 1931, p. 799.

2. CHEONG, W.J., YANG, S.H., ALI, F., J. Sep. Sci., 36, 2013, p. 609-628. 3. TSE SUM BUI, B., HAUPT, K., Anal. Bioanal. Chem., 398, 2010, p. 2481-2492.

4. FAN, D., LI, H., SHI, S., CHEN, X., J. Chromatogr. A, 1470, 2016, p. 27-32.

5. LI, Z., QIN, C., LI, D., HOU, Y., LI, S., SUN, J., J. Pharm. Biomed. Anal. 98, 2014, p. 210-220.

6. ZAIDI, S.A., RSC Adv. 6, 2016, p. 88807-88819.

7. EKOMO, V. MBA, BRANGER, C., BIKANGA, R., FLOREA, A.-M., ISTAMBOULIE, G., CALAS-BLANCHARD, C., NOGUER, T., SARBU, A., BRISSET, H., Biosens. Bioelectron. 112, 2018, p. 156-161.

8. AHMAD, O. S., BEDWELL, T. S., ESEN, C., GARCIA-CRUZ, A., PILETSKY, S. A., Trends in Biotechnology, 37, No. 3, 2019, p. 294-309. 9. VIVEIROS, R., LOPES, M.I., HEGGIE, W., CASIMIRO, T., Chem. Eng. J., 308, 2017, p. 229-239.

10. LI, P., WANG, T., LEI, F., PENG, X., WANG, H., QIN, L., JIANG, J., J. Chromatogr. A, 1502, 2017, p. 30-37.

11. FLOREA, A.-M., IORDACHE, T.-V., BRANGER, C., BRISSET, H., ZAHARIA, A., RADU, A.-L., HUBCA, G., SARBU, A., Eur. Polymer J., 100,2018, p. 48-56

12. ZHAO, J., LIU, W., WANG, J-C., Chem. Biodiv., 12, 2015, p. 309-349. 13. MARRELLI, M., STATTI, G., CONFORTI, F., MENICHINI, F., Mini Rev. Med. Chem., 16, 2016, p. 710-720.

14. WILLIAMS, F.B., SANDER, L.C., WISE, S.A., GIRARD, J., J. Chromatogr. A, 1115, 2006, p. 93-102.

15. WANG, H.Y., KOBAYASHI, T., FUJII, N., Langmuir, 12, 1996, p. 48504856.

16. SARBU, A., IORDACHE, T.V., FLOREA, A.-M., Molecularly Imprinted Polymers (MIPs) Challenges, Uses and Prospects, 3, Nova Publishers, QUINN, T., New York, 2017, p. 119.

17. WANG, H.Y., XIA, S.L., SUN, H., LIU, Y.K, CAO, S.K, KOBAYASHI, T., J Chromatogr B Analyt Technol Biomed Life Sci., 804, 2004, p. 127134.

18. SARBU, A., IANCU, S., DULDNER, M., APOSTOL, S., DIMA, S.-O., IONESCU, E., AVRAMESCU, S., UDREA, I., GAREA, A. S., SANDU, T., SARBU, L., FLOREA, A.-M., OSIM 199/05.03.2013; RO 129825B1/2018. 19. FLOREA, A.-M., IORDACHE, T-V., BRANGER, C., GHIUREA, M., AVRAMESCU, S., HUBCA, G., SARBU, A., Talanta, 148, 2016, p. 37-45. 
20. LAZAU, C., IORDACHE, T.-V., FLOREA, A.-M., ORHA, C., BANDAS, C., RADU, A.-L., SARBU, A., T. ROTARIU, Appl. Surface Sci., 384, 2016, p. 449-458.

21. CHENG, W. X., FAN, F.F, ZHANG, Y., PEI, Z.C., WANG, W.J., PEI, Y.X., Polymers, 9, 2017, p. 135.
22. PEI, Y.X., FAN, F.F, WANG, X.X., FENG, W.W., HOU, Y., PEI, Z.C., Polymers, 9, 2017, p. 469.

23. FLOREA, A.-M., IORDACHE, T-V., ZAHARIA, A., GEORGESCU, B., VOICU, A.E., TSYNTSARSKI, B., HUBCA, G., SARBU, A., Mat. Plast., 54, no. 3,2017, p. 498.

Manuscript received: 8.04 .2019 